\title{
From Deficit to Divergence: Integrating Theory to Inform the Selection of Interventions in Special Education
}

\author{
Tachelle Banks \\ Cleveland State University, Cleveland, USA \\ Email: t.i.banks@csuohio.edu
}

Received 25 December 2013; revised 25 January 2014; accepted 2 February 2014

Copyright (C) 2014 by author and Scientific Research Publishing Inc.

This work is licensed under the Creative Commons Attribution International License (CC BY).

http://creativecommons.org/licenses/by/4.0/

(c) (i) Open Access

\begin{abstract}
Special education provides service and access to students and families who have varied life experiences that manifest as variations in development, learning, and behavior. The contention of this paper supports the notion of refocusing our efforts on developmental and learning theories that take into consideration human variance and individual difference to inform intervention selection in special education. The author briefly discusses the current practice of Special Education in the United States and presents definitions of divergence versus deficit to build the argument that focusing inadequacy of student performance as opposed to variation in student performance can lead to inaccurate identification of appropriate strategies for students with exceptionalities. A definition of deficit model in conjunction with cultural and social implications, with regard to students identified as having emotional and behavior disabilities will be discussed. Emotional intelligence and moral development are introduced as theoretical models that can inform selection and classroom use of preventative mental health curriculum and interventions designed to improve student capacity in emotion-based utility, perspective taking, and decision making.
\end{abstract}

\section{Keywords}

Special Education, Cultural Divergence, Emotional Behavior Disabilities, Preventative Mental Health Curriculum

\section{Introduction}

Special education provides service and access to students and families who have varied life experiences that manifest as variations in development, learning, and behavior. If the initial statement is true and we, as a field, 
understand that the children and youth we serve are different, why is special education couched in a deficit service provision model? This question provides the framework for this paper, which discusses the notion of the divergence of students who receive special education services and aligns interventions with student learning, behavioral differences, and thinking differences. Acknowledging distinction results in increased probability to identify individual students' needs and implement programming based on their differences, which is directly aligned with the explicit purpose of the Individualized Education Plan (IEP). Consequently, special education requires a change in perspective regarding how disability is conceptualized to improve the educational experience of children and youth with exceptionalities, specifically those identified as having emotional behavior disorders (EBD).

The thesis of this paper supports the notion of refocusing our efforts on developmental and learning theories that take into consideration human variance and individual difference to inform intervention selection in special education. The author presents definitions of divergence versus deficit to build the argument that focusing inadequacy of student performance as opposed to variation in student performance can lead to inaccurate identification of appropriate strategies for students with exceptionalities. A definition of deficit model in conjunction with cultural and social implications will be discussed. Emotional intelligence and moral development are introduced as theoretical models that can inform selection and classroom use of preventative mental health curriculum and interventions designed to improve student capacity in emotion-based utility, perspective taking, and decision making.

\section{Special Education}

Special education programs in the United States were made mandatory in 1975 when the United States Congress passed the Education for All Handicapped Children Act (EHA) in response to discriminatory treatment by public educational agencies against students with disabilities. The EHA was later modified to strengthen protections to people with disabilities and renamed the Individuals with Disabilities Education Act (IDEA). The federal laws require states to provide special education consistent with federal standards as a condition of receiving federal funds. IDEA entitles every student to a free and appropriate public education (FAPE) in the least restrictive environment (LRE). To ensure a FAPE, a team of professionals from the local educational agency meet with the student's parents to identify the student's unique educational needs; develop annual goals for the student; and determine the placement, program modification, testing accommodations, counseling, and other special services that the student needs. Parents become a part of the multidisciplinary team, along with the local educational agency professionals, and collaborate with team members to make decisions on educational placement. These choices are recorded in a written IEP. The school is required to develop and implement an IEP that meets the standards of federal and state educational agencies. Parents have the option of refusing special education services for their child.

Under IDEA, students with disabilities are entitled to receive special educational services through their local school district from age three to age 18 or 21 . To receive special education services, a student must demonstrate a disability in one of 13 specific categories, including autism, developmental disability, specific learning disability, intellectual impairment, emotional and/or behavioral disability, intellectual disability, speech and language disability, deaf-blind, visual impairment, hearing impairment, orthopedic or physical impairment, other health impaired(including attention deficit disorder), multiple disabilities, and traumatic brain injury. Depending on the students' individual needs, they may be included, mainstreamed, or placed in a special school, and/or may receive many specialized services in a resource room or self-contained classroom. In addition to academic goals, the goals documented in the IEP may address self-care, social skills, physical, speech, and vocational training. The program placement is an integral part of the process, and typically takes place during the IEP meeting. IDEA has been reauthorized and amended a number of times, most recently in December 2004, and now contains several significant amendments. To receive special education services, disability definitions and labels are based on the notion of deficits. Students qualify for services based on gaps and weaknesses in academic and social emotional performance as compared to students without disabilities. Disability labels can be stigmatizing as they follow students throughout their educational career. The stigma is associated with being defined by the label and subsequent performance deficits. This paper focuses primarily on students identified as having EBD and supports the notion of focusing on divergence and providing special education services that highlight a departure from theories and interventions that are deficit based. 


\section{Deficit versus Divergence}

Deficit highlights inadequacy or insufficiency in student performance. Deficit is defined as a deficiency or impairment in mental or physical functioning or an unfavorable condition or position; a disadvantage. The basis of the term deficit does not relate to the explicit purpose of the profession's vehicle for service provision for children and youth with special learning needs. The “deficit” model focuses on the student as the major problem, neither looking within the environment nor the instructional practices in the classroom. According to this model, the typical procedure is to test the student by determining eligibility for special education and then removing the student from the environment(s) where the problem existed. After more than two decades of federal legislation and implementation of the "deficit" model, there are now mounting concerns about the outcomes of students who have been served in this manner. Despite years of mandated services, many students with mild to moderate disabilities continue to be inadequately served, particularly African American children and youth who are disproportionally identified as having emotional behavior disorders or mild intellectual disabilities (Dunn, 1968; Harry \& Klinger, 2007). Harry and Klinger (2007) reviewed the recent history of special education. The authors stated that the focus on disability has become intertwined with the historical devaluing of minorities in the United States and that the deficit model influences the special education placement process, resulting in a disproportionate placement of some minority groups in special education.

Divergence better qualifies students that receive special education services. The definition of divergence is a difference between two or more things. Divergence is also defined as a deviation from something such as a typical pattern or the process of separating or moving apart to follow different paths or different courses. Students who require special education display variation from typical developmental, learning, or behavioral patterns, resulting in the development of IEPs that are designed to meet diverse learning needs. There is direct alignment between the definition of the divergence and the stated purpose of the IEP.

Deficit highlights inadequacies that do not meet conventional educational expectations. The deficit model currently serves as the conceptual framework for placement in special education. Divergence highlights deviation from typical patterns without associated stigma for nonconformity. Schools should focus on differences rather than on deficits and should be concerned with finding instructional programs that work for challenging and at-risk children and youth. Teachers should monitor his or her own prejudices and carefully consider individual student variation as well as challenges before referring any student, particularly a minority child, for special education.

\section{Deficit Model, EBD, and Cultural Implications}

The deficit model is based on the normative development of students whose homes and communities have prepared them for schooling long before they entered school. Children and youth from different social and cultural backgrounds begin the schooling process at a disadvantage because they deviate from majority social cultural norms and values. They begin school with different preparation and variation in the home with the support of family members who establish and reinforce the goals of schooling. As a result, children and youth from different social and cultural backgrounds are expected to meet expectations that are qualitatively different from their developmental, social, and cultural structures. Consequently, under the auspices of the deficit model, students from different backgrounds quickly become candidates for suspected “disability”.

Considering the deficit model in concert with cultural variables strengthens the contention that students' lack of educational success is contributed to characteristics often rooted in their cultures and communities. As previously discussed, the deficit model frames the problem as one of students and families. The interventions informed by deficit perspectives that are created to improve student underachievement often fail to address problems within schools that depress the performance of certain groups of students. Children and youth of color continue to be overrepresented in special education, and are specifically identified as having EBD (Conchas, 2006; Coutinho \& Oswald, 2000; Harry \& Klingner, 2007; Noguera, 2001; Oakes, 2005). Approximately 475,000 students provided with special education services fall under the category of EBD. Adolescents with EBD are fairly poor in school and post school outcomes (Yeh, Forness, Ho, McCabe, \& Hough, 2004). Students with EBD drop out of school at the highest rate of any category of students with disabilities and only $42 \%$ graduate from high school with a standard diploma (Cullinan \& Sabornie, 2004).

The academic and behavioral problems of students with EBD have been well documented (Kaufman \& Kaufman, 2004). One of the primary characteristics of students with EBD is having classroom behavior prob- 
lems that may be represented by aggression and disruptive off-task behaviors. Most students with EBD also have significant academic difficulties (Kaufman \& Kaufman, 2004). The relationship between student problem behaviors and academic difficulties is complex (Talbott \& Coe, 1997). Some students may exhibit academic difficulties, with aggressive actions, resulting from poor academic instructions, ineffective and negative feedback from teachers, and poor academic self-competence (Kaufman \& Kaufman, 2004). Other students may display aggression before the onset of academic difficulties (Talbott \& Coe, 1997). These students may enter classroom situations without the ability to satisfactorily participate in the educational process (Sutherland, Alder, \& Gunter, 2003). Moreover, the continued disproportionate identification of students of color as having EBD proliferates the negative beliefs regarding students of color and can also result in stereotype threat (Steele, 1997), which causes depressed academic performance.

Focusing on deficits violates fundamental principles of human development. Just as it is recognized that the "multiculturalism" movement is greatly enriching our society, it should be recognized that the narrowing definition of "normal" as it applies to individual characteristics, behavior, and performance is adversely impacting the social and emotional well-being of our children and youth (Obiakor, 2001). Meeting the needs of students who are different requires professionals who think differently about service provision for students with exceptionalities. Professionals who think differently about their profession and service provision understand the notion of being servant leaders, contributors, and change agents to positively impact the lives of families and children. As aptly stated by Harry and Klingner (2007),

"The real problem is the arbitrariness and stigmatizing effects of the entire process. Students shouldn't need a false disability label to receive appropriate support. They also shouldn't acquire that label because they had inappropriate or inadequate opportunities to learn. And they shouldn't end up in programs that don't offer the truly specialized instruction they need" (p. 37).

Students identified as having EBD present a spectrum of disorders that adversely affects their ability to maintain interpersonal relationships and their ability to be successful in traditional classroom environments. The classroom is one of the main contexts where a student's behavior comes into conflict with the rules and norms of the school. The negative impact of deficit perspectives is also evidenced by disproportionately high dropout rates among students of color. It is the responsibility of school-based professionals to determine whether a child needs special education or related services as a result of having EBD (Furlong, Morrison, \& Jimerson, 2004). The following section will define and discuss implications for selecting and using strategies that are based on developmental and learning theories that recognize human variance. It is argued that basing selection of interventions on developmental theory will result in the identification of preventative mental health curriculum and interventions that are better suited to meet the diverse social and emotional learning needs of all children and youth.

\section{Theories That Accentuate Divergence: Emotional Intelligence and Moral Development}

Human development has proven that the difference among differences is very different. Every individual has a unique rate and pattern of development, a unique learning style, and a distinctive collection of personality and behavioral characteristics. In sum, no two human beings are ever exactly alike. Therefore, human variance is the single variable in human development that is constant and universal. Our present-day public school system, more specifically, special education, does not respect this fundamental principle of human development. While there is notable progress (e.g., Response to Intervention), the use of standardized curricula, standardized tests, and standardized procedures as a basis of student achievement and aptitude undermine the basic underpinnings of human development. Moreover, deviation from the standards results in deficit-based labels that are applied and inform special education service provision. In sum, human variation is inherent in all children and youth and should be taken into consideration when providing academic instruction and behavioral support in classroom settings.

Strategies based on behavioral theory have been proven effective and efficient by the normative standard, if the goal is to train children and youth to meet conventional academic and behavioral expectations. Despite the relative effectiveness of behavioral strategies, what remains is continued disproportionate identification of students of color specific to certain disability categories. In addition, the post-school outcomes of children and youth identified as having EBD are disheartening and serve as indicators that the field of special education re- 
quires a refocus of the central ideas of service provision. As a result, this paper proposes a change in perspective for the field of special education by better integrating educational psychology theories of learning and development to inform special education service provision. The following sections present the argument that learning and development theories that acknowledge divergence in human development should be used as the basis to inform identification, placement, instructional planning, and delivery in special education. Emotional intelligence (EI) has been coined a new "hot" intelligence, a subset of social intelligence, proposing the notion that EI is a mental ability that is highly correlated with academic success and an increased aptitude in performance of four constructs that positively impact quality of life (Mayer, Salovey, \& Caruso, 1997, 2000, 2004; Salovey \& Mayer, 1990).

\section{Emotional Intelligence}

EI has been defined as a skill in the case of the trait EI model, a self-perceived ability to have identity, assessment, and control of oneself, others, and groups. Various models and definitions have been proposed of which the ability and trait EI models are the most widely accepted in the scientific literature (Mayer \& Salovey, 1997). Peter Salovey and John D. Mayer (1990) have been the leading researchers on emotional intelligence and their EI mental ability model serves as the theoretical model that is the basis of the contention presented in this chapter. In their influential article Emotional Intelligence, the authors defined emotional intelligence as "the subset of social intelligence that involves the ability to monitor one's own and others' feelings and emotions, to discriminate among them and to use this information to guide one's thinking and actions” (p. 32).

Salovey and Mayer (1990) developed and conceptualized a mental ability model that identified four different factors of EI: the perception of emotion, the ability to reason using emotions, the ability to understand emotion, and the ability to manage emotions. EI is presented as a four branch model of skills that are necessary to demonstrate mental ability. Perceiving emotions is the first step in understanding emotions. In many cases, this might involve understanding nonverbal signals, such as body language and facial expressions. Reasoning with emotions involves using emotions to promote thinking and cognitive activity. Emotions help prioritize to what we pay attention and react; we respond emotionally to things that garner our attention. Understanding that emotions are the feelings that we perceive can carry a wide variety of meanings. If someone is expressing angry emotions, the observer must interpret the cause of his or her anger and what it might mean. For example, if a student is acting angrily, it might mean that he is dissatisfied with his performance; it could also be because he had an altercation with a friend or family member. The ability to manage emotions effectively is a key part of emotional intelligence.

Regulating emotions and responding appropriately to the emotions of self and others are important aspects of emotional management. According to Mayer et al. (1997), the four branches of the emotional intelligence model are "arranged from more basic psychological processes to higher, more psychologically integrated processes. For example, the lowest level branch concerns the (relatively) simple abilities of perceiving and expressing emotion. The highest level branch concerns conscious, reflective regulation of emotion” (Mayer et al., 1997).

\section{Emotional Intelligence: Implications for Classroom Application}

EI states that feelings are recognized as one of three or four basic types of mental operations. The classes of operations include motivation, emotion, cognition, and consciousness (Mayer et al., 1997). The interaction between emotion and cognition comprises EI. Based on the theoretical premise of EI, it could be argued that remediation in thinking and feeling can assist students with managing emotions. As a result, school-based programs should be designed to help children and youth develop emotional and social skills by increasing emotional intelligence.

Rational Emotive Behavior Therapy (REBT) is a cognitive behavior intervention that is based on constructs similar to those represented in the EI mental ability model. REBT states that thinking, feeling, and behaving are interrelated constructs. Traditionally, a clinical approach REBT has been applied in various educational contexts with children and youth. REBT recognizes the influence that cognitions have on behavior and emotions and suggests that all three must be regarded in order to modify emotional disturbances (Walden, DiGiuseppe, \& Dryden, 1992). Ellis (1994) stated that thinking affects, and in some ways creates, individuals' feelings and behaviors; individuals' emotions have a very important impact on their thoughts and actions; and individuals' actions distinctly influence their thoughts and feelings. Consequently, if one of these processes is somehow altered, 
the others are influenced as well. Ellis developed a simple ABC model to address emotional concerns. " $\mathrm{A}$ " is defined as an activating event, and " $\mathrm{B}$ " is defined as a student's belief system about "A." "C" is defined as emotional and behavioral consequences. It was indicated that " $B$ " largely causes " $C$." Disputing intervention, " $D$ " is employed to challenge beliefs (Walden et al., 1992). Irrational beliefs are identified as absolute demands that lead to negative effects (Gregas, 2006). Irrational thoughts or beliefs serve as the basis of REBT and require modification to manage extreme emotions.

REBT consciously recognizes the wide individual differences observed in the way students in school (and elsewhere) react to the same event (DiGiuseppe, 1990). Whether the event is teasing, academic failure, criticism, parental rejection, unfair treatment, or frustrating and difficult tasks, children and adolescents of the same age experience different degrees of adaptive and maladaptive emotions and behavior. REBT is considered a comprehensive intervention that incorporates cognitive restructuring techniques containing emotive and challenging behavioral aspects. The goals in the REBT treatment of school-aged populations are similar to those in adult treatment, although the means vary depending on the cognitive-developmental status and intelligence level of the student (Bernard, 1990). REBT is directed at bringing about a reduction in the intensity of inappropriate, negative emotions of students.

The goals of REBT practitioners are to make students increasingly aware of their self-talk and internal dialogue so they will be able to think more rationally, clearly, and logically (Ellis \& Wilde, 2002). REBT practitioners also try to teach clients to evaluate the content of their beliefs in hopes of allowing students to experience fewer disturbed emotions. Finally, REBT practitioners attempt to help students gain skills using rational-emotive principles so they will act in a more appropriate manner and be better able to achieve their goals in life (Wilde, 1996).

\section{Moral Development}

The premise of moral development is to increase the reasoning ability of students (Kohlberg, 1971; Zionts, 1996). According to Kohlbergian theory, development of moral reasoning can be facilitated via discussion resulting in progression through the developmental stages (Kohlberg \& Gilligan, 1971). Kohlberg (1971) emphasized that it is the way an individual reasons about the dilemma, not the content of the response that determines moral maturity. Kohlberg's stage theory approach to describe moral reasoning defines students who function at pre-conventional, conventional, and post-conventional levels of development (Kohlberg, 1971; Kohlberg \& Gilligan, 1971; Lerner, 2002).

The pre-conventional level is marked by compliance with conventional expectations (Stage one) because of the threat of negative outcomes. Stage two introduces the child's ability to consider others in terms of "fairness." In essence, the child wants to be treated the same as others or equal to others. Individuals functioning at preconventional reasoning levels have little regard for others and therefore may disregard standards of conduct regardless of the setting or context (Kohlberg, 1971; Kohlberg \& Turiel, 1971; Lerner, 2002). Stage three of the introduction of the conventional level of development depicts a transformation of the child, where "I" includes "we." Acceptance from others and what others think takes the forefront of this stage. The child demonstrates a concern for others but only in relation to what others think of the child (Kohlberg, 1971; Zionts, 1996). Stage four readdresses the concept of "fairness." Fairness, in this stage, relates to the group and common rules for the group. Students functioning at conventional stages of reasoning are more inclined to please others and may show more regard for standards of conduct (Kohlberg \& Turiel, 1971; Lerner, 2002; Zionts, 1996). Stage five is included in the post-conventional level. Stage five is a profound individual who considers others in the truest sense, as true as a human being can get. They may be those individuals concerned with civil rights and social justice, recognizing that these concepts are not always reflective in society or protected by societal laws (Kohlberg, 1971; Kohlberg \& Gilligan, 1971; Lerner, 2002). Kohlberg’s (1971) theory suggests that stage progression ( 1 - 4) occurs during grades K-12. The argument proposed in this study is that students with EBD may function at pre-conventional stages and, therefore, demonstrate a decreased ability to assume the perspectives of others.

\section{Moral Development: Educational Implications for Classroom Application}

The nature and scope of problems in special education for students with EBD are overwhelming. An inability to develop and maintain effective relationships with peers and adults is often one of the characteristics associated with students who have been diagnosed with EBD. The premise of moral development is the idea of increasing the reasoning ability of students. The goal of moral education is to promote moral development and improve 
reasoning so that students can better examine situations or conflicts and choose from the best available alternatives. In consideration of Kohlbergian theory, moral education should extend beyond teaching moral knowledge to the development of moral reasoning by facilitating progression through the developmental stages. Therefore, it is assumed that moral education will enhance the student's ability to competently employ independent decision-making skills and consider the perspectives of others.

Perspective taking, the ability to consider another person's point of view, has been viewed as a major basis of moral development. Age serves as a tentative predictor for perspective taking; this may indicate that social abilities and perspective taking abilities may differ regardless of age (Dixon \& Moore, 1990). Students identified as having EBD may show reversal or lack of progression in social-cognitive development (Damon, 1980). If students with EBD, despite age, are functioning at lower levels of social-cognitive development, this may affect their ability to assume the perspective of another person or demonstrate skills that may be age appropriate but are not appropriate for their level of stage development. To address the complex needs of children with EBD, strategies that recognize the relevance of developmental stage theory seem to show promise (Lerner, 2002; Zionts, 1996).

The term moral education is used in this chapter to refer to practices that have an emphasis on education in the development of stage progression and promote independent decision-making skills. Lickona (1996) describes moral education as conscious efforts by schools, families, and communities to help young people understand, care about, and act upon core ethical values. Gibbs (2003) stated that positive moral potential means respecting students and holding them accountable as persons who are capable of thinking and acting responsibly as well as helping others to do the same. Bebeau and Thoma (1999) include that instructional processes should contribute to effective moral decision-making skills, noting that a basic understating is required to resolve complex and moral problems. Students' abilities to reason, examine situations, and make choices that are considerate of themselves and others is the underlying message and that curriculum can be designed and implemented to foster moral decision-making skills.

The teacher's role in fostering moral development has been highlighted in research in an attempt to identify their responsibilities to facilitate cognitive structural change in students and to stimulate students' ability to assume another's perspective. It should be noted that to promote stage progression, it is imperative to ascertain the present level of developmental stage functioning. An awareness of students' stages of moral development on the part of the teachers can provide a basis for identifying and discussing moral dilemmas (Clare \& Gallimore, 1996). The argument is that students may be functioning at lower levels of moral development in spite of chronological age and, therefore, the role of the teacher is to provide moral development instruction, activities, and interactions that facilitate moral development stage progression by improving student perspective taking and decision-making skills.

The EI and Moral Development theories serve as examples of how learning and developmental theories can serve as the basis of selection and use of preventative mental health curriculum and intervention strategies to meet the diverse learning needs of children and youth. EI tells us that students who lack the mental ability to identify and regulate emotions would benefit from instruction that teaches the skills included in the EI ability model. REBT is one such strategy that teaches abilities in the EI model. Moral development theory states that students who lack the ability to assume the perspective of others would benefit from curriculum that focuses on promoting stage progression. Moral development curriculum provides the opportunity for students to assume the roles of others and engage in discussion that advances students from one moral development stage to the next.

\section{Integrating Theory to Inform the Selection of Interventions}

Not all children and youth will respond the same way to scripted interventions; they require intervention strategies that are designed to meet their wide-ranging needs in order to be successful during and after school years. Training children and youth maybe suitable for classrooms and contrived environments, but special education must better prepare students to be successful in life-beyond the scope of the classroom. Professionals would benefit from understanding the importance of emotional intelligence and the role it plays in the greater development of all students. In addition, the integration of moral development in the classroom curriculum will result in benefits beyond the classroom.

In preparing children and youth to deal with life in an increasingly complex society, it is important that schools devote attention to well organized and theoretically sound programs employing a preventative approach 
to mental health. Vernon (1989) stated that the goal of affective programming is to create "learning experiences through which children can gain knowledge about themselves and their feelings and can learn how to apply this knowledge in solving problems and coping with situations throughout life” (p. 469). Preventative mental health curricula should focus upon developing in children an awareness of self, feelings, self in relation to others, and decision-making and problem-solving skills (Vernon, 1989; Zionts, 1996). REBT principles have been used with children and adolescents in schools and are found to be an effective intervention with many commonly occurring difficulties. REBT's cognitive restructuring technique contains several emotive and challenging behavioral aspects that can be argued to have the potential to meet the broad needs of students with EBD.

Moral development curriculum can foster an atmosphere that allows the consideration of the viewpoint of others (Zionts, 1996). Developmental intervention is aimed at providing an opportunity for students to assume the perspective of others (Gibbs, Arnold, Ahlborn, \& Cheesman, 1984). Perspective taking, the ability to consider another person's point of view, has been viewed as a major basis of moral development. The introduction of a moral development curriculum into a special education classroom might enhance the reasoning ability of students with EBD. Moral development curriculum will provide the opportunity for students with EBD to look at situations from their own perspective and consider the perspectives of others. Moral development strategies have been researched and examined to determine effectiveness with students that incorporates service delivery, a service learning program that includes mentoring relationships, using moral dilemmas in children's literature, a peer confrontation system, dilemma discussions as a basis of creating a democratic community (Kohlberg, 1971), and equipping youth to help one another through consideration of problem situations and group discussion (Gibbs, 2003).

\section{Conclusion}

Rather than devoting extensive resources to finding out whether students "have" deficits, we should devote those resources to assessing students' exact instructional and social emotional needs. Focusing on human variation as opposed to pathology has been argued as a viable option for moving special education from a deficit model to a model that embraces divergence, keeping in mind that difference is not unique but is the one variable that resonates in all people, including children and youth.

\section{References}

Bebeau, M. J., \& Thoma, S. J. (1999). “Intermediate Concepts” and the Connection to Moral Education. Educational Psychology Review, 11, 343-360. http://dx.doi.org/10.1023/A:1022057316180

Bernard, M. E. (1990). Rational-Emotive Therapy with Children and Adolescents: Treatment Strategies. School Psychology Review, 19, 294-303.

Clare, L., \& Gallimore, R. (1996). Using Moral Dilemmas in Children's Literature as a Vehicle for Moral Education and Teaching Reading Comprehension. Journal of Moral Education, 25, 325-341. http://dx.doi.org/10.1080/0305724960250305

Conchas, G. Q. (2006). The Color of School Success: Race and High-Achieving Urban Youth. New York: Teachers College Press.

Coutinho, M. J., \& Oswald, D. P. (2000). Disproportionate Representation in Special Education: A Synthesis and Recommendations. Journal of Child and Family Studies, 9, 135-156. http://dx.doi.org/10.1023/A:1009462820157

Cullinan, D., \& Sabornie, E. J. (2004). Characteristics of Emotional Disturbance in Middle and High School Students. Journal of Emotional \& Behavioral Disorders, 12, 157-167. http://dx.doi.org/10.1177/10634266040120030301

Damon, W. (1980). Patterns of Change in Children's Social Reasoning: A Two-Year Longitudinal Study. Child Development, 51, 1010-1017. http://dx.doi.org/10.2307/1129538

DiGiuseppe, R. (1990). Rational-Emotive Assessment of School Aged Children. School Psychology Review, 19, $287-293$.

Dixon, J. A., \& Moore, C. F. (1990). The Development of Perspective Taking: Understanding of Information and Perspective Differences. Child Development, 61, 1502-1513. http://dx.doi.org/10.2307/1130759

Dunn, L. (1968). Special Education for the Mildly Retarded: Is Much of It Justifiable? Exceptional Children, 35, 5-22.

Ellis, A. (1994). Reason and Emotion in Psychotherapy. Secaucus, NJ: Carol Publishing Group.

Ellis, A., \& Wilde, J. (2002). Case Studies in Rational Emotive Behavior Therapy with Children and Adolescents. New Jersey: Upper Saddle River.

Furlong, M. J., Morrison, G. M., \& Jimerson, S. R. (2004). Externalizing Behaviors of Aggression and Violence and the 
School Context. In R. B. Rutherford, M. M. Quinn, \& S. R. Mathur (Eds.), Handbook of Research in Behavioral Disorders. New York: The Guilford Press.

Gibbs, J. C. (2003). Moral Development and Reality: Beyond the Theories of Kohlberg and Hoffman. Thousand Oaks, CA: Sage.

Gibbs, J. C., Arnold, K. D., Ahlborn, H. H., \& Cheesman, F. L. (1984). Facilitation of Sociomoral Reasoning in Delinquents. Journal of Consulting and Clinical Psychology, 52, 37-45. http://dx.doi.org/10.1037/0022-006X.52.1.37

Gregas, A. J. (2006). Applying Rational Emotive Behavior Therapy to Multicultural Classrooms. Multicultural Learning and Teaching, 1, 24-34. http://dx.doi.org/10.2202/2161-2412.1008

Harry, B., \& Klingner, J. K. (2007). Discarding the Deficit Model. Educational Leadership, 64, 16-21.

Kaufman, A. S., \& Kaufman, N. L. (2004). Kaufman Assessment Battery for Children (2nd ed.). Circle Pines, MN: American Guidance Service.

Kohlberg, L. (1971). From Is to Ought: How to Commit the Naturalistic Fallacy and Get Away with It in the Study of Moral Development. New York: Academic Press.

Kohlberg, L., \& Gilligan, C. (1971). The Adolescent as a Philosopher: The Discovery of the Self in a Postconventional World.Daedalus, 100, 1051-1086.

Kohlberg, L., \& Turiel, E. (1971). Moral Development and Moral Education. In G. S. Lesser (Ed.), Psychology and Educational Practice (pp. 410-465).Glenview, IL: Scott, Foresman \& Company.

Lerner, R. M. (2002). Concepts and Theories of Human Development (3rd ed.). Mahwah, NJ: Lawrence Erlbaum Associates.

Lickona, T. (1996). Eleven Principles of Effective Character Education. The Journal of Moral Education, 25, 93-100. http://dx.doi.org/10.1080/0305724960250110

Mayer, J. D., \& Salovey, P. (1997). What Is Emotional Intelligence? In P. Salovey, \& D. Sluyter (Eds.), Emotional Development and Emotional Intelligence: Implications for Educators (pp. 3-31). New York: Basic Books.

Mayer, J. D., Salovey, P., \& Caruso, D. (1997). Emotional IQ Test (CD ROM). Needham, MA: Virtual Knowledge.

Mayer, J. D., Salovey, P., \& Caruso, D. R. (2000). Models of Emotional Intelligence. In R. J. Sternberg (Ed.), Handbook of Human Intelligence (2nd ed., pp. 396-420). New York: Cambridge.

Mayer, J. D., Salovey, P., \& Caruso, D. R. (2004). Emotional Intelligence: Theory, Findings, and Implications. Psychological Inquiry, 15, 197-215. http://dx.doi.org/10.1207/s15327965pli1503_02

Noguera, P. (2001). Racial Politics and the Elusive Quest for Excellence and Equity in Education. Education and Urban Society, 34, 18-41. http://dx.doi.org/10.1177/0013124501341003

Oakes, J. (2005). Keeping Track: How Schools Structure Inequality (2nd ed.). New Haven, CT: Yale University Press.

Obiakor, F. E. (2001). Developing Emotional Intelligence in Learners with Behavioral Problems: Refocusing Special Education. Behavioral Disorders, 26, 321-331.

Salovey, P., \& Mayer, J. D. (1990). Emotional Intelligence. Imagination, Cognition, and Personality, 9, $185-211$. http://dx.doi.org/10.2190/DUGG-P24E-52WK-6CDG

Steele, C. M. (1997). A Threat in the Air: How Stereotypes Shape Intellectual Identity and Performance. American Psychologist, 52, 613-629. http://dx.doi.org/10.1037/0003-066X.52.6.613

Sutherland, K. S., Alder, N., \& Gunter, P. L. (2003). The Effect of Varying Rates of Opportunities to Respond to Academic Requests on the Classroom Behavior of Students with EBD. Journal of Emotional \& Behavioral Disorders, 11, $239-248$. http://dx.doi.org/10.1177/10634266030110040501

Talbott, E., \& Coe, M. G. (1997). A Developmental View of Aggression and Achievement. In T. E. Scruggs, \& M. A. Mastropieri (Eds.), Advances in Learning and Behavioral Disabilities (Vol. 11, pp. 69-86). Greenwich, CT: JAI Press.

Vernon, A. (1989). Assessment and Treatment of Childhood Problems: Applications of Rational-Emotive Therapy. Counseling and Human Development, 22, 1-12.

Walden, S., DiGiuseppe, R., \& Dryden, W. (1992). A Practitioner's Guide to Rational Emotive Therapy. New York: Oxford.

Wilde, J. (1996). The Efficacy of Short-Term Rational-Emotive Education with Fourth-Grade Students. Elementary School Guidance \& Counseling, 31,131-138.

Yeh, M., Forness, S. R., Ho, J., McCabe, K., \& Hough, R. L. (2004). Parental Etiological Explanations and Disproportionate Racial/Ethnic Representation in Special Education Services for Youths with Emotional Disturbance. Behavioral Disorders, 29, 348-358.

Zionts, P. (1996). Teaching Disturbed and Disturbing Students: An Integrative Approach. Austin: Pro-Ed. 